\title{
Two Novel Hexadepsipeptides with Several Modified Amino Acid Residues Isolated from the Fungus Isaria
}

by Gudihal Ravindra ${ }^{a}$ ), Rappal. S. Ranganayaki ${ }^{a}$ ), Srinivasa $\operatorname{Raghothama~}^{\mathrm{b}}$ ), Mandayam C. $\operatorname{Srinivasan}^{\mathrm{c}}$ ), Richard D. Gilardi ${ }^{\mathrm{d}}$ ) Isabella L. Karle ${ }^{\mathrm{d}}$ ), and Padmanabhan Balaram*a ${ }^{\mathrm{e}}$ )

a) Molecular Biophysics Unit, Indian Institute of Science, Bangalore-560012, India (phone: +91-80-22932337; fax: +91-80-23600683; e-mail: pb@mbu.iisc.ernet.in)

b) Sophisticated Instruments Facility, Indian Institute of Science, Bangalore-560012, India $\left.{ }^{c}\right)$ National Chemical Laboratory, Pune, India

d) Laboratory for the Structure of Matter, Naval Research Laboratory, Washington, DC 20375-5341, USA

e) Chemical Biology Unit, Jawaharlal Nehru Centre for Advanced Scientific Research, Bangalore-560064, India

Two new cyclohexadepsipeptides have been isolated from the fungus Isaria. Fungal growth in solid media yielded hyphal strands from which peptide fractions were readily isolable by organic-solvent extraction. Two novel cyclodepsipeptides, isaridin A and isaridin B, have been isolated by reverse-phase HPLC, and characterized by ESI-MS and ${ }^{1} \mathrm{H}-\mathrm{NMR}$. Single crystals of both peptides have been obtained, and their 3D structures were elucidated by X-ray diffraction. The isaridins contain several unusual amino acid residues. The sequences are cyclo( $\beta$-Gly-HyLeu-Pro-Phe-NMeVal-NMePhe $)$ and cyclo( $\beta$-Gly-HyLeu- $\beta$-MePro-Phe-NMeVal-NMePhe), where NMeVal is $N$-methylvaline, NMePhe $N$-methylphenylalanine, and HyLeu hydroxyleucine (=2-hydroxy-4-methylpentanoic acid). The two peptides differ from one another at residue 3, isaridin A having an $(S)$-proline at this position, while $\beta$-methyl- $(S)$-proline $(=(2 S, 3 S)-2,3,4,5$-tetrahydro-3-methyl-1H-pyrrole-2carboxylic acid) is found in isaridin B. The solid-state conformations of both cyclic depsipeptides are characterized by the presence of two cis peptide bonds at HyLeu(2)-Pro(3)/HyLeu(2)- $\beta$-MePro(3) and $\mathrm{NMeVal}(5)-\mathrm{NMePhe}(6)$, respectively. In isaridin A, a strong intramolecular H-bond is observed between $\mathrm{Phe}(4) \mathrm{CO} \cdots \mathrm{HN} \beta$-Gly(1), and a similar, but weaker, interaction is observed between $\beta$-Gly(1)CO $\cdots \mathrm{HNPhe}(4)$. In contrast, in isaridin $\mathrm{B}$, only a single intramolecular H-bond is observed between $\beta$-Gly(1)CO $\cdots$ HNPhe(4).

Introduction. - According to Bennett and Bentley, 'secondary metabolism represents the splendid, idiosyncratic diversity of nature, endowing different species with specific solutions to biological problems' [1]. Secondary metabolites are organic compounds of relatively low molecular mass produced by many actinomycetes, fungi, higher plants, and a few prokaryotes. The distinction between primary and secondary metabolic processes has been the subject of debate [1][2]. According to Verpoorte's definition, 'secondary metabolites are compounds with a restricted occurrence in taxonomic groups, that are not necessary for a cell (organism) to live, but play a role in the interaction of the cell (organism) with its environment, ensuring the survival of the organism in its ecosystem' [2]. They are generally produced by specific taxa during the later or stationary phase of growth. Secondary metabolites produced by organisms have found various industrial applications, e.g., as therapeutic agents, flavoring agents, coloring agents, odoring agents, antibiotics, etc. [3]. Recent interest in isolating and characterizing new secondary metabolites has grown with the recognition of their great importance in biotechnological applications. Fungi are an excellent source material for organic molecules of unusual structure and composition. Screening of previously lessoften-investigated genera and species for novel molecules has intensified globally. 
Hyphomycetous fungi, which are characterized by abundant conidia formation and lack a dominant sexual cycle, are attractive targets for screening programs to discover novel metabolites of value. Species of Aspergillus, Penicillium, Acremonium, and Fusarium are among the most-often-investigated, and several valuable secondary metabolites and enzymes with commercial applications have been discovered in these genera of fungi [4]. In the present study, we used a species of Isaria isolated in pure culture, for the purification of novel peptides from its sporulating structures that are differentiated en masse after a period of vegetative growth.

Isaria belong to the group of hyphomycetes and are characterized by their mycelia growing rapidly on conventional mycological media. In the strain studied by us, the sporulation occurs in the form of numerous synnemata consisting of closely compacted hyphal strands, growing erect from the basal mycelial colony and bearing numerous unicellular small round spores.

Results and Discussion. - Isaria grown on a solid medium yielded a luxuriant harvest of hyphae (Fig. 1, inset). MALDI Mass spectral analysis of the hyphae, directly spotted along with the matrix on a target plate, yielded a spectrum in which two signals at $\mathrm{m} / \mathrm{z}, 705$ and 744 were predominant (Fig. 1). In addition, mass peaks in the range 550-4000 were also obtained. Under these conditions, low-molecular-weight substances (less than $600 \mathrm{Da}$ ) may be obscured by matrix peaks. Inspection of the pattern of peaks at $m / z, 720$ and 744 suggested that these signals corresponded to $[M+\mathrm{H}]^{+}$and $[M+\mathrm{Na}]^{+}$species, respectively, given the fact that the MALDI-MS signals were not very accurate $( \pm 2 \mathrm{Da})$. The high intensity of the peaks at $\mathrm{m} / \mathrm{z} 705$ and 720 was suggestive of hydrophobic molecules abundantly present on the cell surface, which are readily ionized in the matrix plume after laser irradiation. The signals at $\mathrm{m} / \mathrm{z} 637$ and 593 corresponded to already characterized cyclic pentadepsipeptides isolated from Isaria felina [5][6]. The high abundance of previously unreported metabolites prompted us to undertake their isolation and characterization.

In Fig. 2, an HPLC trace of the hyphal extract obtained by triturating dry hyphal powder with an organic solvent $\left(\mathrm{EtOH}, \mathrm{MeOH}\right.$, or $\left.\mathrm{CHCl}_{3}\right)$. Several components were resolved, and ESI-MS analysis permitted assignment of the molecular masses indicated. A comparison of HPLC peak intensities (UV detection at 226 and $254 \mathrm{~nm}$ ) revealed the presence of strongly absorbing aromatic groups in the compounds corresponding to the metabolites with the masses 704 and $718 \mathrm{Da}\left([M+\mathrm{H}]^{+}\right)$. HPLC Purification readily yielded pure samples of both metabolites.

In Fig. 3, the 500-MHz ${ }^{1} \mathrm{H}-\mathrm{NMR}$ spectra of the two isolated metabolites are shown, which immediately established their peptidic nature, as evidenced by the presence of amide NH resonances and the characteristic patterns of amino acid spin systems. Interestingly, only two NH resonances were observed in each case, suggesting the presence of either hydroxy acid or $N$-alkylated residues. The two intense $s$ at $\delta_{\mathrm{H}} 3.02$ and 3.14, found for both peptides, are indicative of the presence of two $N$-methylamino acids. The NMR spectra of the two peptides showed a great deal of similarity, with one major difference; the metabolite with mass $718 \mathrm{Da}\left([M+\mathrm{H}]^{+}\right)$gave rise to a $d$ at $\delta_{\mathrm{H}}$ 1.06 due to a $\mathrm{CH}-\mathrm{Me}$ group, which was absent in the metabolite with $\mathrm{m} / \mathrm{z} .704$ ([M+ $\mathrm{H}]^{+}$). This suggested that the metabolites differed only by the presence of a single $\mathrm{Me}$ group at an aliphatic C-atom in the 718-Da peptide, consistent with the mass difference 

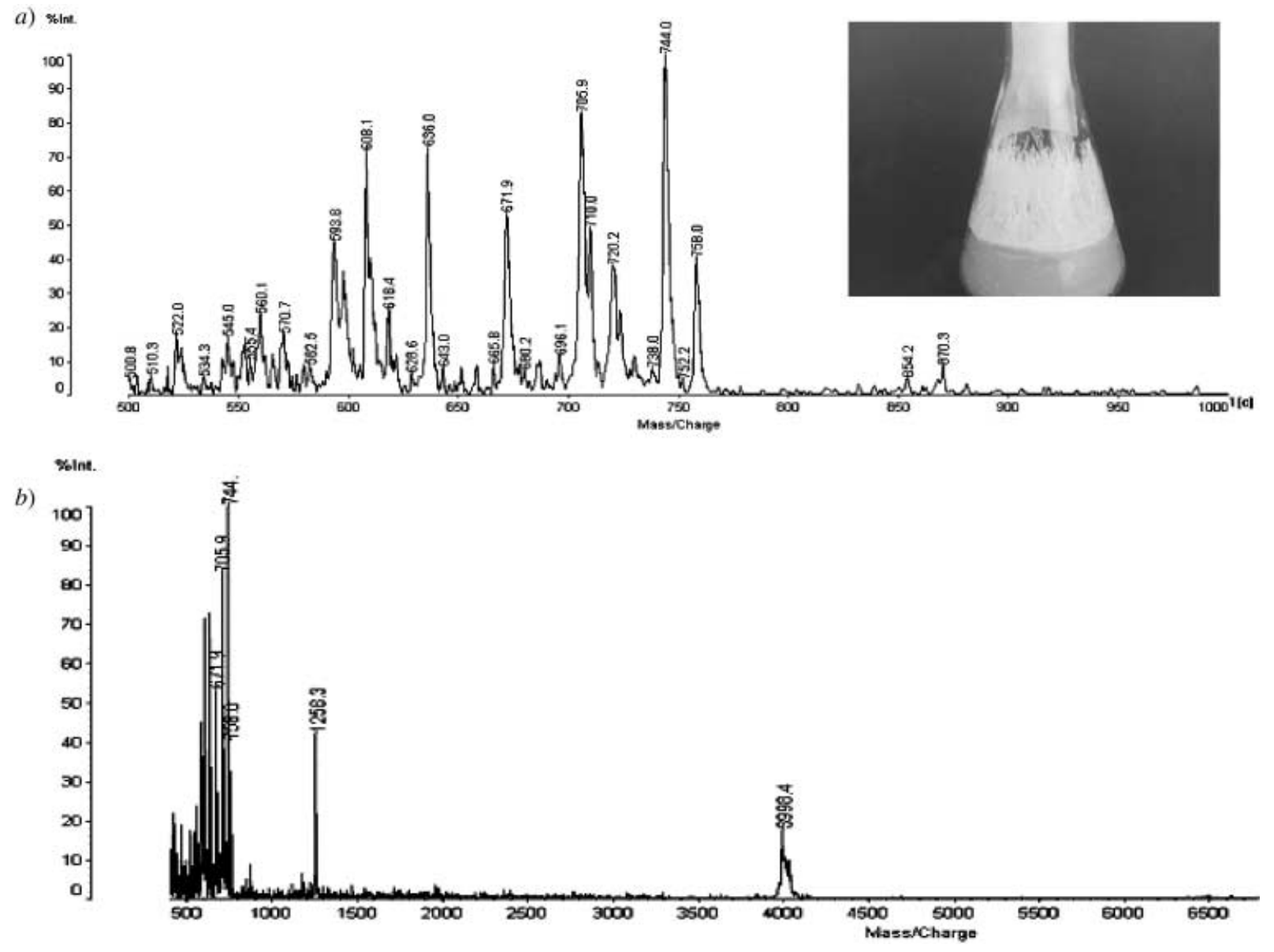

Fig. 1. MALDI Mass spectra of hyphae of Isaria in the range of a) 500-1000 Da, and b) 500-7500 Da. The hyphae were directly spotted onto a plate and irradiated. The inset shows hyphae growing as whitish, threadlike structures. 


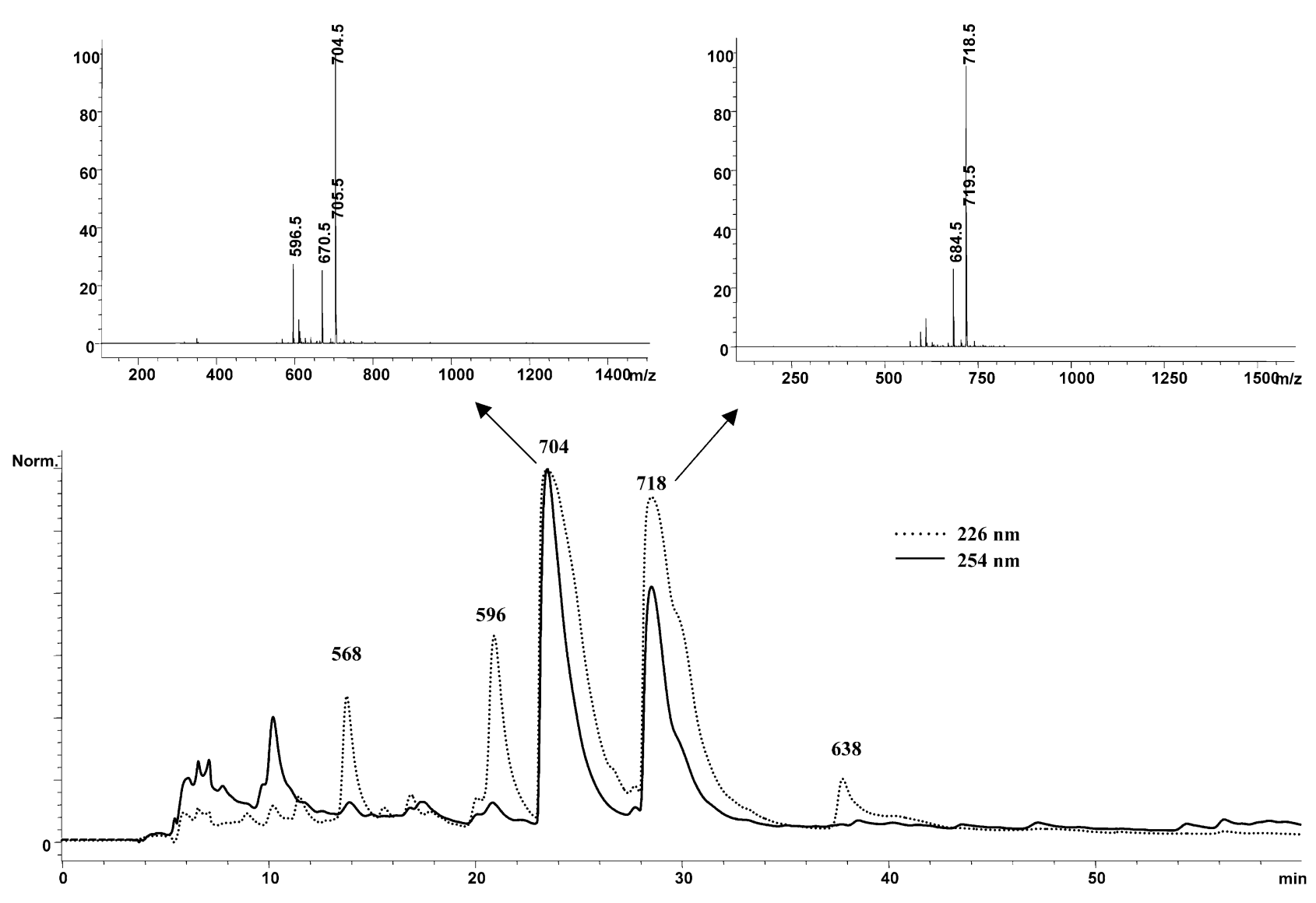

Fig. 2. HPLC/MS Traces of a crude hyphal extract of Isaria (MeCN solution). Bottom: a comparison of HPLC-UV peak intensities (at 226 and $254 \mathrm{~nm}$ ), the corresponding mass signals $(\mathrm{m} / \mathrm{z})$ are marked. Top: ESI-MS Spectra of metabolites with $\mathrm{m} / z 704$ and $718\left([\mathrm{M}+\mathrm{H}]^{+}\right)$. 
of $c a .14 \mathrm{Da}$. Further analysis of the NMR spectra are described subsequently. The resolution of the structural problem was hastened by the ready crystallization of both peptides from $\mathrm{MeCN} / \mathrm{H}_{2} \mathrm{O}$ mixtures after HPLC purification. The two peptides will, hereafter, be referred to as isaridin $\mathrm{A}\left([M+\mathrm{H}]^{+}=704 \mathrm{Da}\right)$ and isaridin $\mathrm{B}([M+$ $\left.\mathrm{H}]^{+}=718 \mathrm{Da}\right)$.

a)

$\operatorname{cyclo}(\beta$-Gly-HyLeu-Pro-Phe-NMeVal-NMePhe)

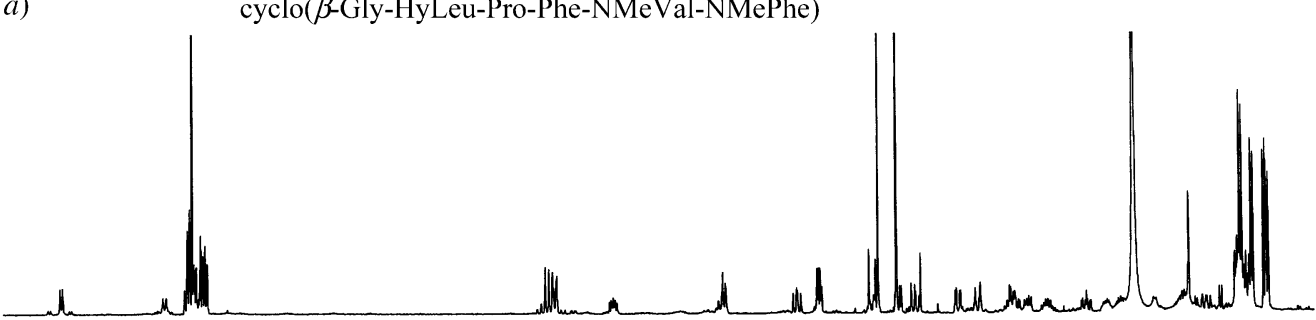

b) $\operatorname{cyclo}(\beta$-Gly-HyLeu- $\beta$-MePro-Phe-NMeVal-NMePhe)

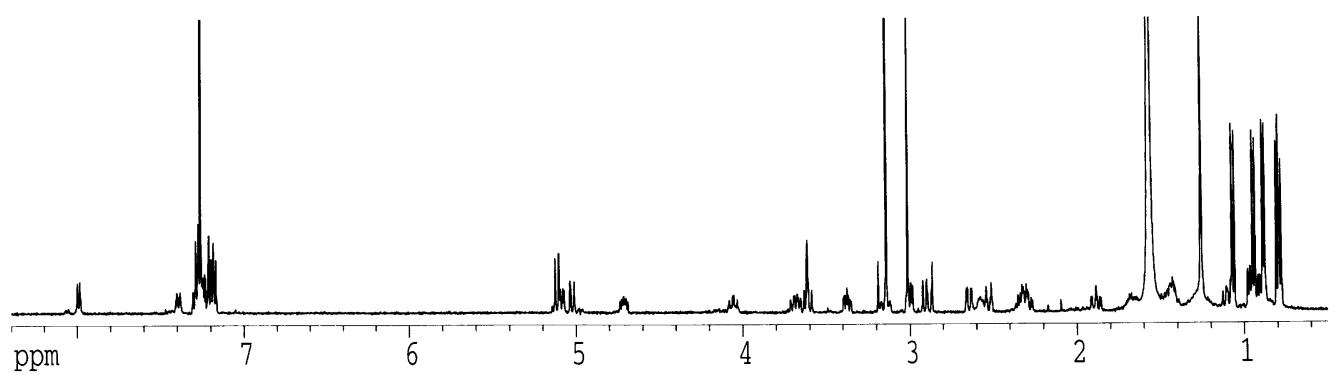

Fig. 3. ${ }^{1} H-N M R$ Spectra $\left(500 \mathrm{MHz}, \mathrm{CDCl}_{3}\right)$ of a) isaridin A, and b) isaridin B. $\delta_{\mathrm{H}}$ in ppm, $T=300 \mathrm{~K}$.

Molecular Structures of Isaridin A and B. In Fig. 4, a view of the molecular structures of the two isaridins, as determined by single-crystal X-ray diffraction, is shown. Isaridin A is a cyclic depsipeptide containing a single hydroxy acid: the leucine analog 2-hydroxy-4-methylpentanoic acid (HyLeu). The amino acid sequence is $\operatorname{cyclo}(\beta$-Gly-HyLeu-Pro-Phe-NMeVal-NMePhe) (Fig. 4,a). Notably, the peptide contains two $N$-methylated residues, $\operatorname{Val}(5)$ and $\mathrm{Phe}(6)$, and one $\beta$-amino acid residue, $\beta$ glycine $\left.{ }^{1}\right)$.

Isaridin $\mathrm{A}$ has a proline residue in the 3-position, while in isaridin $\mathrm{B}$, this is a $\beta$ methylproline (3-methylproline) residue, i.e., the sequence is cyclo $(\beta$-Gly-HyLeu- $\beta$ MePro-Phe-NMeVal-NMePhe. The configuration at the $\alpha$-C-atom is $(S)$, with the $\beta$ Me group being anti (trans) relative to the amide $\mathrm{C}=\mathrm{O}$ group (Fig. 4,b).

1) It should be noted that ' $\beta$-glycine' has been referred to as ' $\beta$-alanine' in the literature. However, the growing body of work on synthetic peptides necessitates a revision of nomenclature, with the term ' $\beta$ alanine' being used to refer to the $\beta$-residue obtained by backbone homologation of alanine ( $\beta^{3}$-HAla, $\beta^{3}$ homoalanine, 3-aminopropanoic acid [7]). 
a)
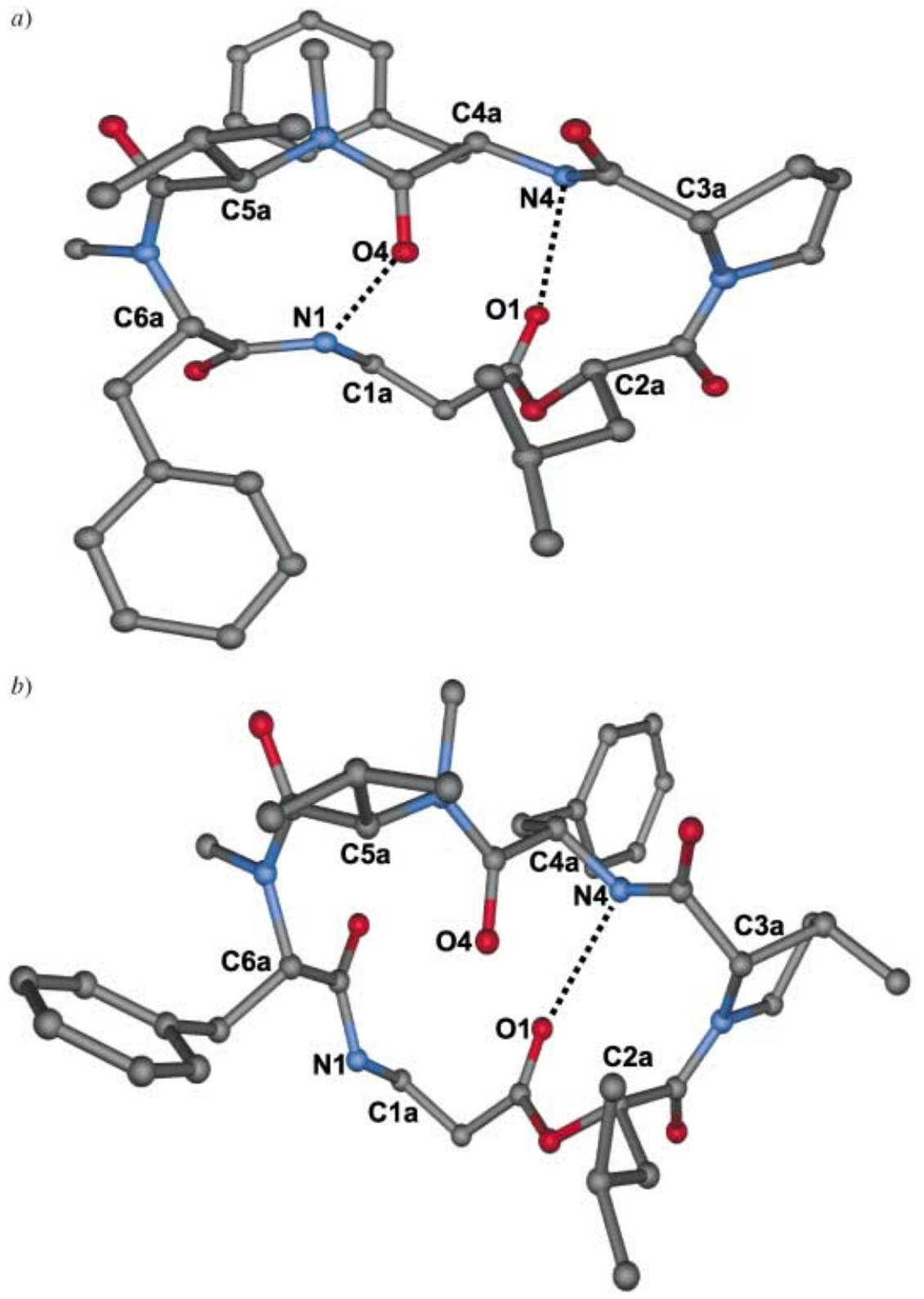

Fig. 4. X-Ray crystal structures of a) isaridin A, and b) isaridin B. Strong intramolecular H-bonds are indicated by dashed lines.

An unusual feature of the isaridins is the presence of a large number of modified residues in the sequence. In isaridin $\mathrm{A}$, four out of six residues are nonproteinogenic: two $N$-methyl residues, one $\beta$-residue, and one $\alpha$-hydroxy acid. Isaridin B possesses, in addition to these, even a $\beta$-MePro residue. The constitution of the isaridins may be 
contrasted with those of previously characterized cyclodepsipeptides, isariin and isariins $\mathrm{B}-\mathrm{D}$ (sequences: isariin and isariin $\mathrm{B}$; cyclo(Gly-Val- $\left.{ }^{\mathrm{D}} \mathrm{Leu}-\mathrm{Ala}-\mathrm{Val}-{ }^{\mathrm{D}} \mathrm{Hyd}\right)$, where ${ }^{\mathrm{D}} \mathrm{Hyd}$ is $\mathrm{D}-\beta$-hydroxydodecanoic acid (isariin) or $\mathrm{D}-\beta$-hydroxynonanoic acid (isariin $\mathrm{B}$ ); isariin $\mathrm{C}$ and $\mathrm{D}$ : cyclo(Gly-Ala- ${ }^{\mathrm{D}}$ Leu-Ala-Val- $\left.{ }^{\mathrm{D}} \mathrm{Hyd}\right)$, where ${ }^{\mathrm{D}} \mathrm{Hyd}$ is $\mathrm{D}-\beta$ hydroxynonanoic acid (isariin $\mathrm{C}$ ) or $\mathrm{D}-\beta$-hydroxyheptanoic acid (isariin $\mathrm{D}$ ). In the isariins, five of the six residues are $\alpha$-amino acids, generally aliphatic in nature, with the sixth residue being a $\beta$-hydroxy acid [5][6].

The presence of $\beta$-MePro (= $(2 S, 3 S)$-2,3,4,5-tetrahydro-3-methyl-1H-pyrrole-2carboxylic acid) in isaridin $\mathrm{B}$, established in the present study, is particularly noteworthy. The assignment of the configuration is based on the L-configuration assumed for the other amino acid residues. The $\beta$-MePro residue has been observed in several natural products, including roseotoxin B (Trichothecium roseum) [8], roseocardin (Trichothecium roseum) [9], paraherquamide A (Penicillium paraherquei) [10], and asperparaline (Aspergillus japonicus) [11]. The configuration of the $\beta$-MePro residues in these examples is $(S)$, however, the $(R)$-form occurs in bottromycin $\mathrm{A}_{2}$ (Streptomyces bottropenis) [12] and polyoxypeptin (Streptomyces sp.) [13]. The configuration of the $\beta$-MePro residue in destruxin $\mathrm{A}_{5}$ (Aschersonia) [14] has not been established. The biosynthetic origin of $\beta$-MePro in paraherquamide, a potent anthelminthic alkaloid, has been extensively investigated by the Williams group at Colorado, and strong evidence for Ile as the precursor of $\beta$-MePro, biosynthesized via oxidative cyclization, has been presented [15]. An alternative route involving direct methylation of Pro with $S$-adenosylmethionine has been suggested for bottromycin [16]. The presence of related isaridins that possess both Pro and $\beta$-MePro residues is suggestive of a biosynthetic origin that involves direct Pro methylation.

Conformation of Cyclic Depsipeptides. In Fig. 4, the depsipeptide (backbone) conformations of isaridin $\mathrm{A}$ and $\mathrm{B}$ are shown. The backbone torsion angles and the $\mathrm{H}-$ bond parameters are summarized in Tables 1 and 2 . Notably, in both peptides, the $\operatorname{HyLeu}(2)-\operatorname{Pro}(3) / \mathrm{HyLeu}(2)-\beta$-MePro(3) and the $\mathrm{NMeVal}(5) / \mathrm{N}-\mathrm{MePhe}(6)$ amide bonds adopt a cis conformation $\left(\omega \approx 0^{\circ}\right)$. In isaridin $\mathrm{A}$, two potential intramolecular H-bonds, Phe(4)CO $\cdots \mathrm{HN} \beta$-Gly(1) and $\beta$-Gly(1)CO $\cdots$ HNPhe(4), are observed. Of these, the $\mathrm{N}(4) \cdots \mathrm{O}(1)$ interaction appears weaker, with a significantly greater $\mathrm{H} \cdots \mathrm{O}$ distance and poorer $\mathrm{H}$-bond angle $\left(\Varangle \mathrm{NHO}=120.6^{\circ}\right)$ compared to the $\mathrm{N}(1) \cdots \mathrm{O}(4)$ $\mathrm{H}$-bond. In isaridin $\mathrm{B}$, only one strong intramolecular $\mathrm{H}$-bond is observed; $\beta$-Gly(1)CO $\cdots$ HNPhe(4). The observed distance between Phe(4)CO $\cdots \mathrm{HN} \beta$-Gly(1) is $3.73 \AA$ $(\mathrm{N}(1) \cdots \mathrm{O}(4))$, which is considerably outside the limits generally considered indicative of such interactions. The unfavorable orientation of the N(1)-atom for cross-ring $\mathrm{H}$ bond formation is evident from Fig. 4,b. The conformational difference between the two peptides can be traced to large changes in the torsion angles $\phi_{1}[\beta$-Gly(1)] and $\psi_{6}[\mathrm{NMePhe}(6)]$. The change corresponds to different tilts of the peptide unit connecting residues $\mathrm{C}\left(1^{\alpha}\right)$ to $\mathrm{C}\left(6^{\alpha}\right)$ in the cyclic systems. This is clearly seen in Fig. 5, which shows a superposition of the two peptide structures, $a$ ) with, and $b$ ) without side chains.

In the canonical structure of all-trans cyclic hexapeptides, two opposing $\beta$-turns are linked on either side by single residues adopting extended-strand conformations [17][18]. The isaridins provide examples, where the turning segments have the central peptide unit in the cis conformation, analogous to type-VI turns, which have been 

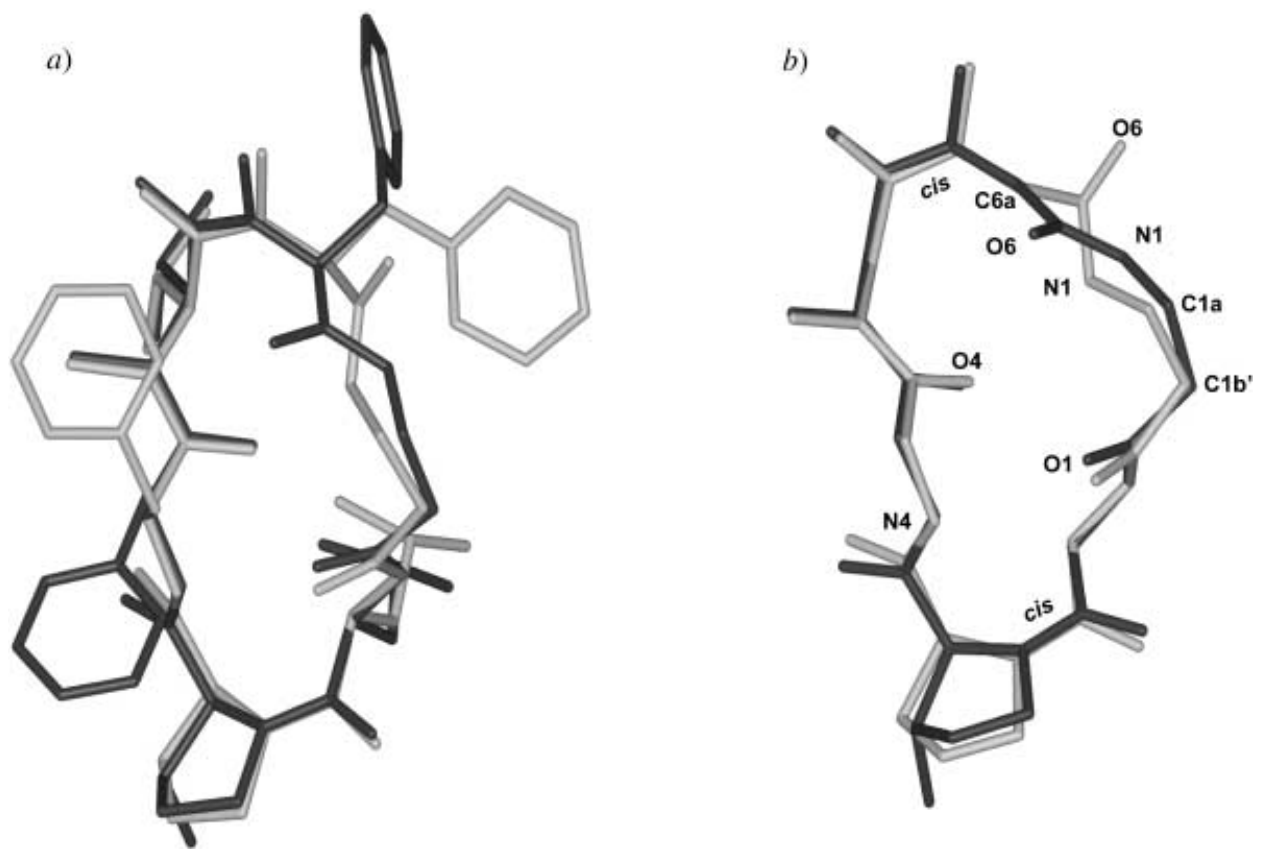

Fig. 5. Superposition of a) the molecular structures, and b) the backbone structures of isaridin $A$ (grey) and isaridin $B$ (black), as determined by $X$-ray diffraction. Note the conformational differences between the two peptides for $\phi_{1}\left(\beta\right.$-Gly(1)) and $\psi_{6}(\mathrm{NMePhe}(6))$. The r.m.s.d. value for the $\mathrm{C}^{\alpha}$-atoms was $0.271 \AA$.

Table 1. Backbone Torsion Angles in the Crystal Structures of Isaridin A and B

\begin{tabular}{llcr}
\hline Residue & Torsion angle $\left(^{\circ}\right)$ & Isaridin A & Isaridin B \\
\hline$\beta$-Gly(1) & $\phi_{1}$ & -125.2 & 128.7 \\
& $\theta_{1}$ & -60.8 & -71.3 \\
& $\psi_{1}$ & 125.4 & 137.3 \\
& $\omega$ & -170.6 & 176.5 \\
HyLeu(2) & $\phi_{2}$ & -59.7 & -58.9 \\
& $\psi_{2}$ & 146.3 & 147 \\
Pro(3)/ $\beta$-MePro(3) & $\omega$ & 10.9 & 14.5 \\
& $\phi_{3}$ & -77.9 & -83.6 \\
& $\psi_{3}$ & -9.7 & 0.6 \\
Phe(4) & $\omega$ & 171.4 & 174.3 \\
& $\phi_{4}$ & -62.1 & -79.3 \\
NMeVal(5) & $\psi_{4}$ & 141.5 & 155.3 \\
& $\omega$ & 179.1 & 174.7 \\
NMePhe(6) & $\phi_{5}$ & -105 & -112 \\
& $\psi_{5}$ & 104.8 & 95.2 \\
& $\omega$ & 6.8 & 7.4 \\
& $\phi_{6}$ & -125.2 & -109 \\
\hline
\end{tabular}


Table 2. Hydrogen-Bonding Parameters for Isaridin $A$ and $B$. 'W' denotes $\mathrm{H}_{2} \mathrm{O}$ molecules. Crystallographically determined symmetry relations are given in the footnotes.

\begin{tabular}{|c|c|c|c|c|}
\hline Donor & Acceptor & $d(\mathrm{~N} \cdots \mathrm{O})[\AA]$ & $d(\mathrm{H} \cdots \mathrm{O})[\AA]$ & $\Varangle(\mathrm{NHO})\left[{ }^{\circ}\right]$ \\
\hline \multicolumn{5}{|c|}{ Isaridin A: } \\
\hline $\mathrm{N}(1)$ & $\mathrm{O}(4)$ & 2.847 & 1.969 & 165.32 \\
\hline $\mathrm{N}(4)$ & $\mathrm{O}(1)$ & 3.081 & 2.524 & 120.61 \\
\hline W1 & $\mathrm{O}(3)$ & 2.956 & & \\
\hline W2 & $\mathrm{W} 1$ & 2.897 & & \\
\hline W1 & $\left.\mathrm{O}(2)^{\mathrm{a}}\right)$ & 2.901 & & \\
\hline W2 & $\left.\mathrm{O}(5)^{\mathrm{b}}\right)$ & 2.957 & & \\
\hline \multicolumn{5}{|c|}{ Isaridin $\mathrm{B}$ : } \\
\hline $\mathrm{N}(1)$ & $\left.\mathrm{W} 2^{\mathrm{c}}\right)$ & 2.961 & 2.16 & \\
\hline $\mathrm{N}(4)$ & $\mathrm{O}(1)$ & 2.989 & 2.31 & 132.24 \\
\hline W1 & $\left.O(3)^{d}\right)$ & 2.894 & & \\
\hline W1 & $\left.\mathrm{O}(6)^{\mathrm{e}}\right)$ & 2.899 & & \\
\hline W2 & W1 & 2.841 & & \\
\hline W2 & $\left.\mathrm{O}(5)^{\mathrm{e}}\right)$ & 2.903 & & \\
\hline
\end{tabular}

defined for proteins [19]. Crystals of both peptides contain $\mathrm{H}_{2} \mathrm{O}$ molecules, which assist the peptides assembling into sheets (Fig. 6). These assemblies of isaridin A and B have much in common. In each crystal, rows of the cyclic peptide molecules are linked in two-dimensional (2D) arrays by $\mathrm{H}$-bonds to $\mathrm{H}_{2} \mathrm{O}$ molecules. One difference concerns the conformation about the $\mathrm{N}(1) \mathrm{H}$ moiety, which results in different $\mathrm{H}$-bonding. In isaridin $\mathrm{A}, \mathrm{N}(1) \mathrm{H}$ forms an interior cross-ring $\mathrm{N}(1) \mathrm{H} \cdots \mathrm{O}(4) \mathrm{H}$-bond, whereas in isaridin $\mathrm{B} \mathrm{N}(1) \mathrm{H}$ is directed outwards, forming an additional $\mathrm{H}$-bond to the $\mathrm{H}_{2} \mathrm{O}$ molecule W2 (Fig. 6). Another difference is that in the crystal of isaridin B the peptide molecules are repeated simply by translation (triclinic space group $P 1$ ), while in that of isaridin $\mathrm{A}$ adjacent molecules in a row are related by a two-fold screw operation (orthorhombic space group $P 2_{1} 2_{1} 2_{1}$ ).

NMR Analysis. The isaridins A and $\mathrm{B}$ are readily soluble in a variety of organic solvents and give rise to extremely well-dispersed ${ }^{1} \mathrm{H}$-NMR spectra in $\mathrm{CDCl}_{3}$, as shown in Fig. 7. Complete assignment of the H-atom resonances was accomplished by means of a combination of gradient COSY, TOCSY, and ROESY spectra. It can be seen from Table 3 that the chemical shifts for the corresponding residues of both peptides are similar, except for Pro(3), where substantial differences are observed.

In Fig. 8, the COSY spectra of the two peptides are depicted. The presence of the $\beta$ MePro residue in isaridin B is evident from the connectivities of the resonances at $\delta_{\mathrm{H}}$ 2.57 and 1.06. In Fig. 9, partial ROESY spectra of isaridins A and B are shown, which established the cis geometry for the peptide HyLeu(2)Pro(3)/HyLeu(2) $\beta$-MePro(3) moieties, as evidenced by the $\mathrm{C}^{\alpha} \mathrm{H} / \mathrm{C}^{\alpha} \mathrm{H}$ NOEs observed between residues 2 and 3 in both peptides. The $\mathrm{C}^{\alpha} \mathrm{H} / \mathrm{C}^{\alpha} \mathrm{H}$ NOEs between the $\alpha$-H-atoms of NMeVal(5) and NMePhe(6), as anticipated for a cis peptide geometry, could not be clearly detected because of the limited chemical-shift separation of these resonances. 
a)
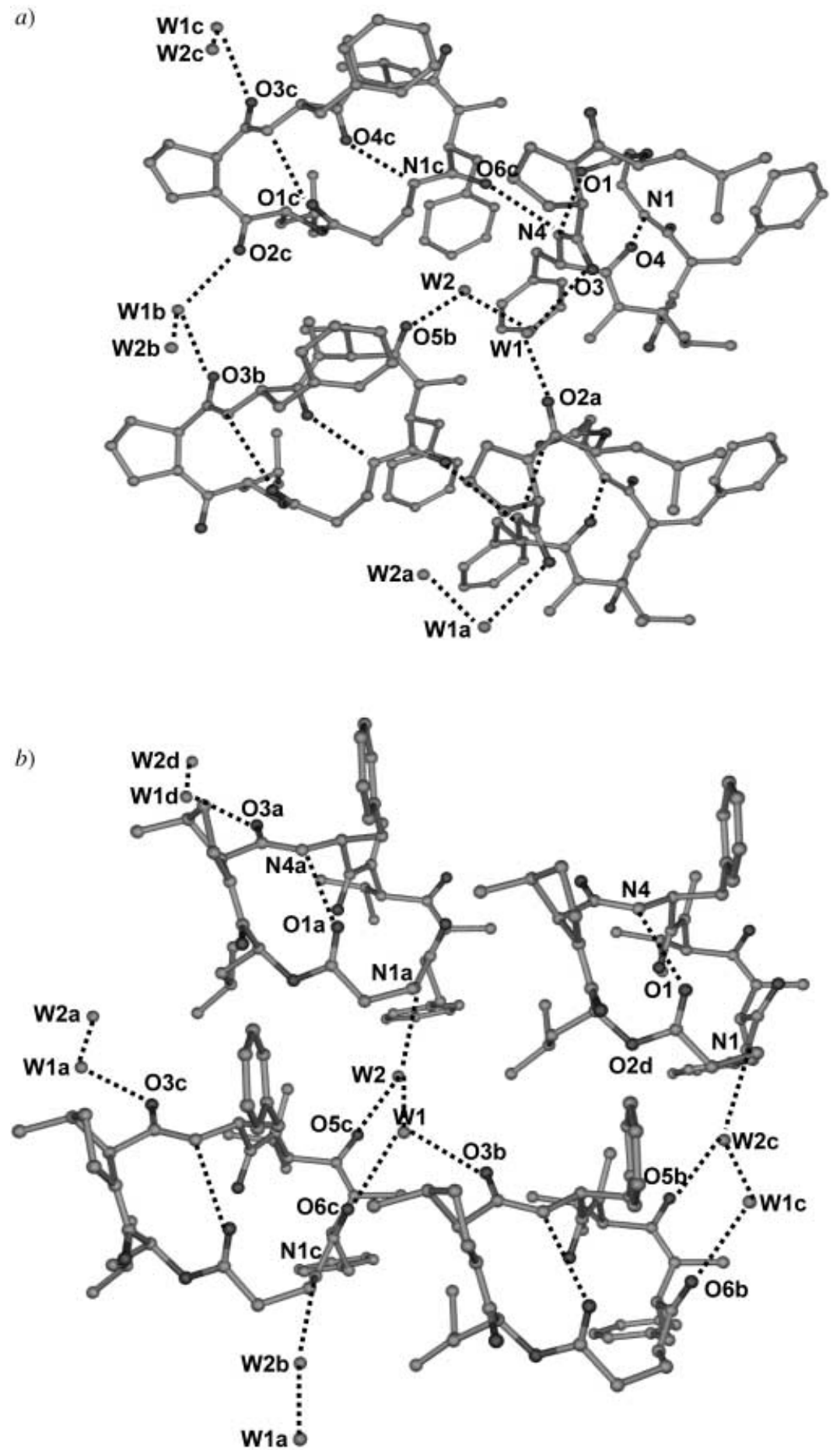

Fig. 6. Lattice structures in the crystals of a) isaridin A, and b) isaridin B. Two $\mathrm{H}_{2} \mathrm{O}$ molecules (designated 'W') mediate the peptide assembly into sheets. 
a)

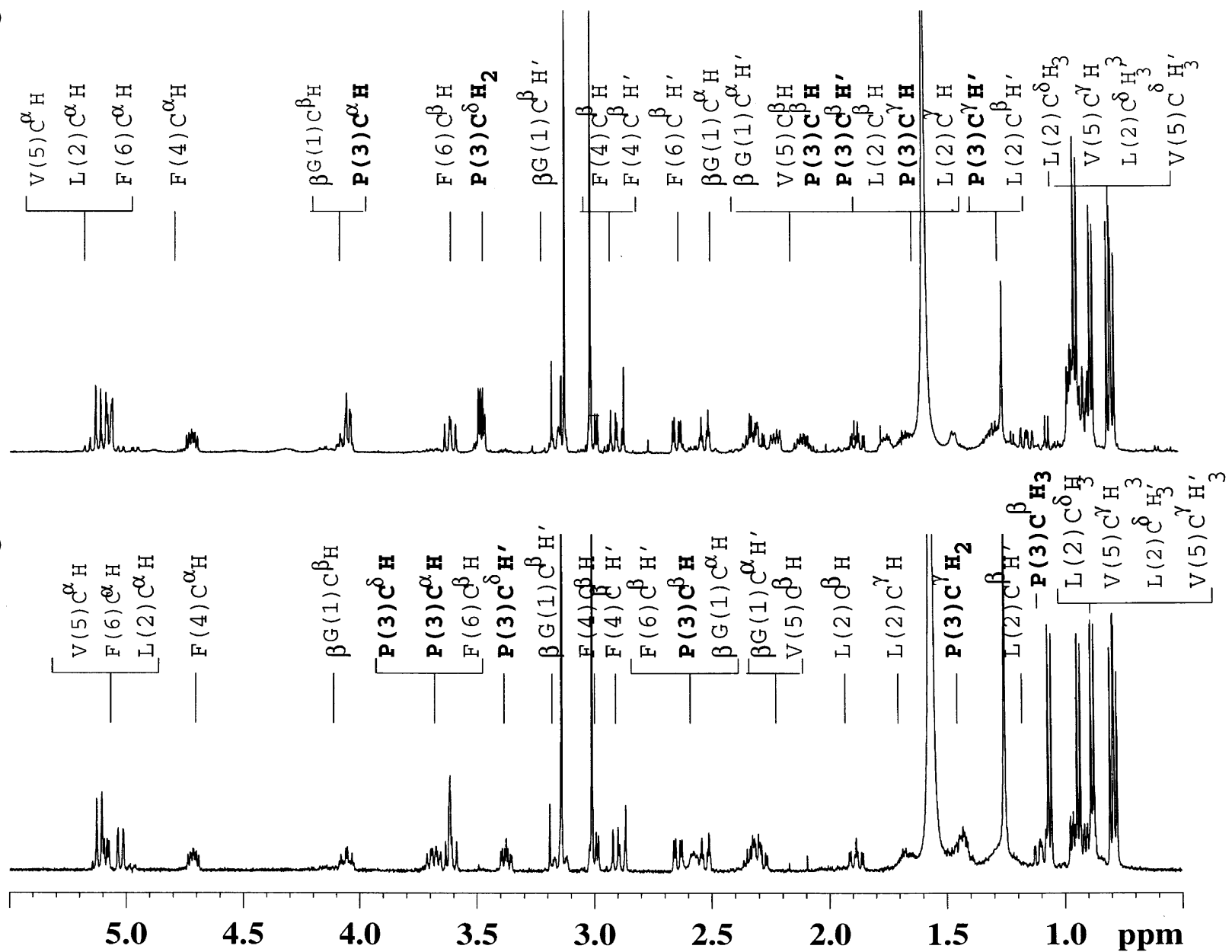



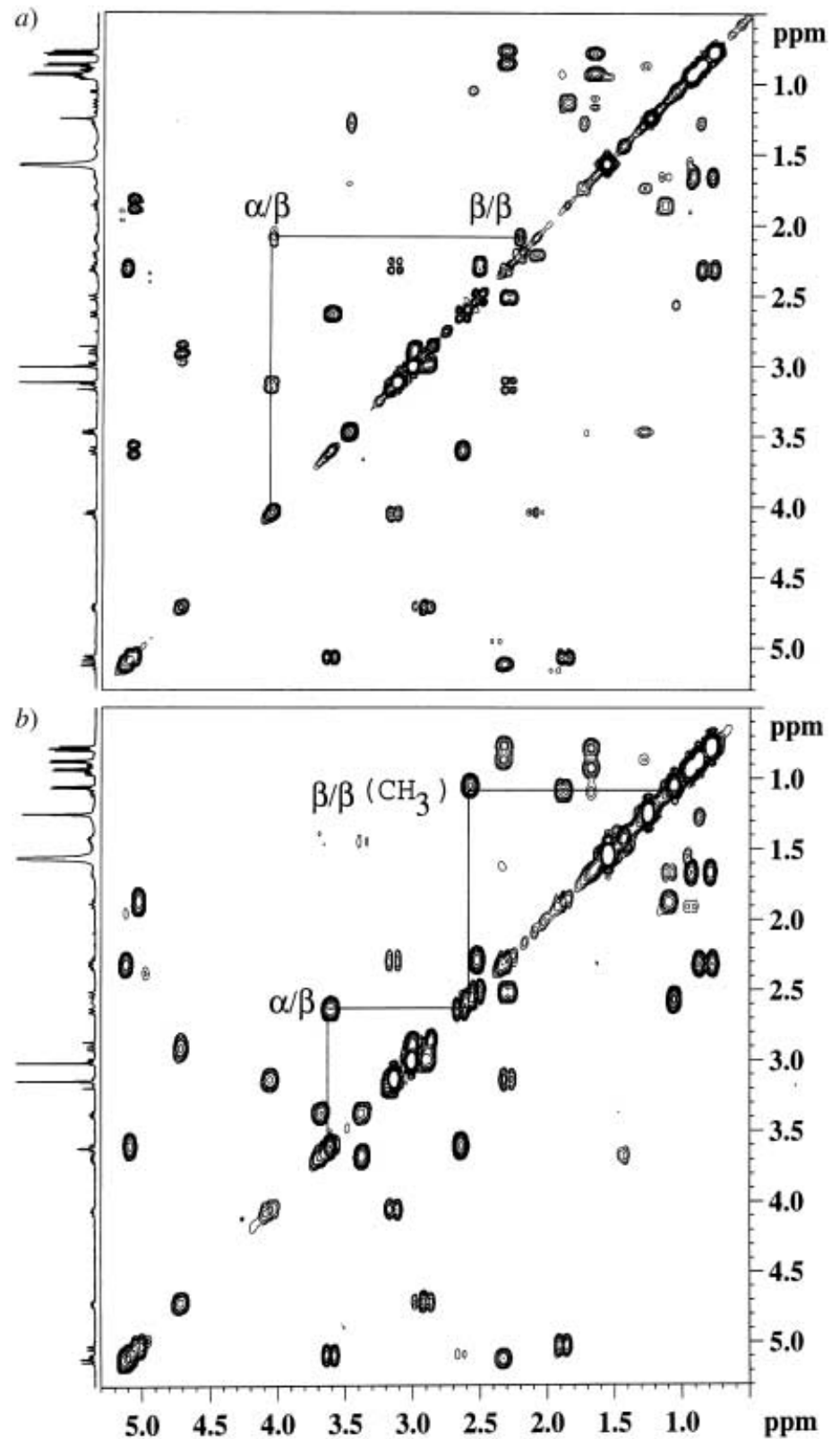

Fig. 8. ${ }^{1} \mathrm{H},{ }^{1} \mathrm{H}$ COSY Spectra $\left(500 \mathrm{MHz}, \mathrm{CDCl}_{3}\right)$ of a) isaridin $A$, and b) isaridin $B$

Conclusions. - A strain of the hyphomycete Isaria has been shown to grow rapidly in solid media with hyphal strands developing erect from a basal mycelial colony. Direct mass-spectral examination of the fungal hyphae revealed the presence of several 
a)

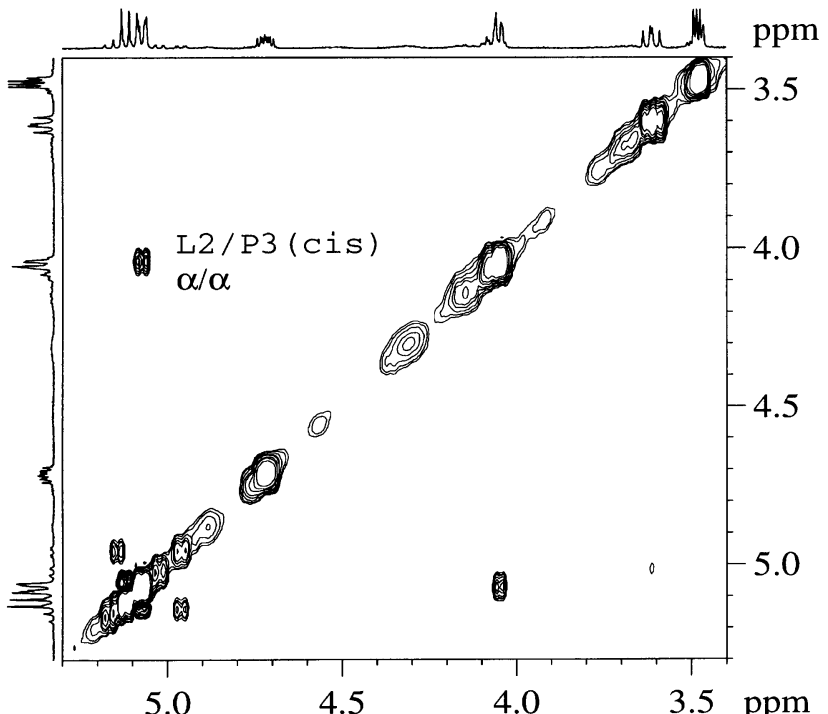

b)

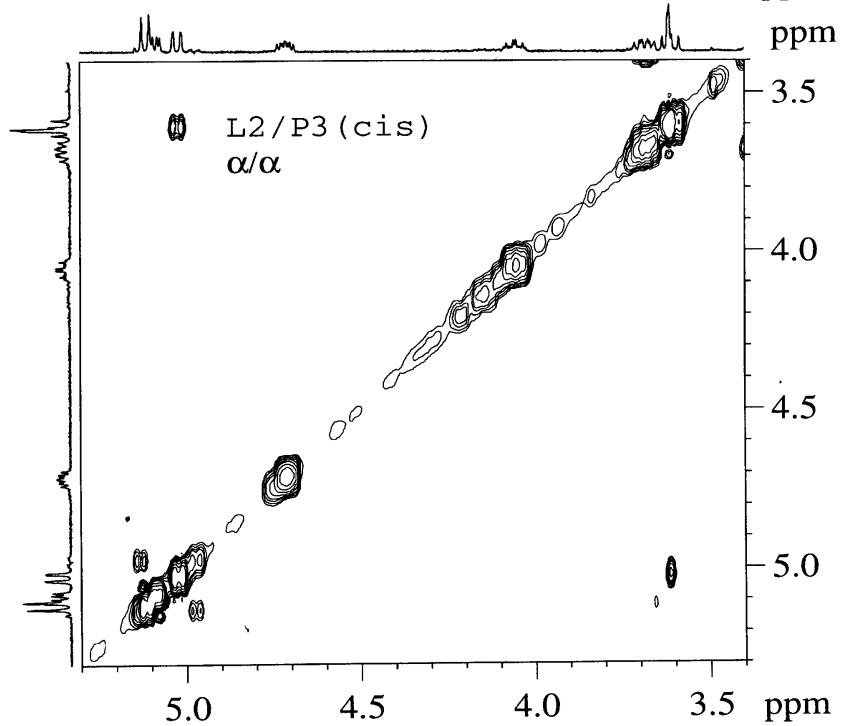

Fig. 9. Partial ROESY spectra (500 MHz, $\mathrm{CDCl}_{3}$ ) of a) isaridin $A$, and b) isaridin $B . T=300 \mathrm{~K}$.

secondary metabolites with masses in the range 550 to $4000 \mathrm{Da}$. Two major components were isolated and shown to be novel cyclic hexadepsipeptides, named isaridin A and B. Crystal-structure analysis revealed that these isaridins possess an unusually high number of modified residues. The established sequences are cyclo $(\beta$-Gly-HyLeu-ProPhe-NMeVal-NMePhe $)$ for isaridin $\mathrm{A}$, and cyclo( $\beta$-Gly-HyLeu-Pro- $\beta$-MePhe-NMeVal-NMePhe) for isaridin B. The molecules adopt backbone conformations with two cis 
Table 3. ${ }^{1} H$-NMR Chemical Shifts (in ppm) for Isaridin $A$ and $B\left(500 \mathrm{MHz}, \mathrm{CDCl}_{3}, 300 \mathrm{~K}\right)$

\begin{tabular}{|c|c|c|c|c|c|c|}
\hline Residue & $\mathrm{NH}$ & $\mathrm{H}-\mathrm{C}^{\alpha}$ & $\mathrm{H}-\mathrm{C}^{\beta}$ & $\mathrm{H}-\mathrm{C}^{\gamma}$ & $\mathrm{H}-\mathrm{C}^{\delta}$ & Other \\
\hline \multicolumn{7}{|l|}{ Isaridin $\mathrm{A}$ : } \\
\hline$\beta$-Gly(1) & 7.42 & $2.52 / 2.33$ & $4.08 / 3.14$ & & & \\
\hline HyLeu(2) & - & 5.07 & $1.87 / 1.15$ & 1.66 & $0.94 / 0.80$ & \\
\hline Pro(3) & - & 4.05 & $2.22 / 2.10$ & $1.74 / 1.29$ & $\left.3.41^{\mathrm{a}}\right)$ & \\
\hline Phe(4) & 8.04 & 4.72 & $2.99 / 2.90$ & & & 7.27/7.18 (arom.) \\
\hline NMeVal(5) & - & 5.12 & 2.30 & $0.87 / 0.78$ & & $3.13(\mathrm{MeN})$ \\
\hline NMePhe(6) & - & 5.07 & $3.61 / 2.64$ & & & $\begin{array}{l}7.27 / 7.20 \text { (arom.) } \\
3.02(\mathrm{MeN})\end{array}$ \\
\hline \multicolumn{7}{|l|}{ Isaridin $\mathrm{B}$ : } \\
\hline HyLeu(2) & - & 5.02 & $1.88 / 1.10$ & 1.67 & $0.94 / 0.80$ & \\
\hline$\beta$-MePro(3) & - & 3.65 & $\left.2.57^{b}\right)$ & $\left.1.45^{\mathrm{c}}\right)$ & $3.70 / 3.38$ & \\
\hline Phe(4) & 7.99 & 4.72 & $3.01 / 2.90$ & & & 7.28/7.18 (arom.) \\
\hline NMeVal(5) & - & 5.12 & 2.29 & $0.88 / 0.78$ & & $3.14(\mathrm{MeN})$ \\
\hline NMePhe(6) & - & 5.09 & $3.62 / 2.64$ & & & $\begin{array}{l}\text { 7.28/7.20 (arom.) } \\
3.01(\mathrm{MeN})\end{array}$ \\
\hline
\end{tabular}

a) $\mathrm{H}_{2} \mathrm{C}^{\delta}$ Group. ${ }^{\text {b }}$ ) $\mathrm{Me}-\mathrm{C}^{\beta}: 1.06$ ppm. $\left.{ }^{\mathrm{c}}\right) \mathrm{H}_{2} \mathrm{C}^{\gamma}$ Group.

peptide bonds in the crystalline state, as established by X-ray diffraction. They differ in constitution from Isaria depsipeptides characterized in earlier studies.

Secondary metabolites from Isaria have been previously shown to have insecticidal properties. Despite their abundance in the fungal hyphae of the Isaria strain examined, we have, so far, not found a specific biological activity for these new compounds. According to Bennett and Bentley, 'much of the morphological diversity that is the basis of our great taxonomic systems is readily discerned with the naked eye. With the exception of pigments, the chemical diversity expressed in secondary metabolism is less obvious and therefore, perhaps, more mysterious. Yet it, too, represents the beguiling and beautiful manifestations of genotypic differentiation that species have perfected during their evolutionary history' [1]. The biological role of the isaridins, whose biosynthesis undoubtedly requires considerable metabolic investment by the producing organism, certainly merits further investigation.

This research has been supported by a program grant in the area of Molecular Diversity and Design by the Department of Biotechnology, Government of India. The work at the Naval Research Laboratory was supported by the National Institutes of Health, grant GM30902, and the Office of Naval Research. We thank S. Aravinda for help in generating Fig. 5.

\section{Experimental Part}

Strain Isolation and Culture for Depsipeptide Production. The Isaria strain was isolated by incubating rat dung in moist chambers. From the developing synnemata, single spore colonies were isolated and maintained in pure cultures on mycological media such as potato dextrose agar or carrot agar. For production of the synnemata in large quantities for extraction, the following procedure was adopted. Peeled potatoes $(200 \mathrm{~g})$ and peeled carrots $(100 \mathrm{~g})$ were cut into small cubes, boiled in tap water, and blended. Agar $(20 \mathrm{~g})$ was added to this mixture, made up to 11 , and distributed in 200- to 250-ml portions in 500-ml Erlenmeyer flasks. The flasks were plugged with cotton and autoclaved at 15 -lbs pressure for $20 \mathrm{~min}$. After cooling and solidification of the agar, the flasks were inoculated with a spore suspension prepared from 10-15-day-old slant culture, and inoculated at r.t. 
$\left(26-28^{\circ}\right)$. Formation of synnemata from the mycelial colony was observed within $5-7 \mathrm{~d}$, reaching a maximum after $10-12 \mathrm{~d}$

Extraction of Depsipeptides. The synnemata appeared as whitish aerial thread-like structures. They were harvested $(2 \mathrm{~g})$ by picking them with fine forceps. The hyphae were then suspended in EtOH $(200 \mathrm{ml})$, homogenized for $15 \mathrm{~min}$ in a blender, and then filtered through filter paper, yielding a white milky filtrate. The residue was again treated in a similar manner, the filtrate was collected, pooled, dried $\left(\mathrm{Na}_{2} \mathrm{SO}_{4}\right)$, and evaporated to dryness, to yield a brownish-colored crude solid $(10 \mathrm{mg})$. Alternatively, the hyphae were blended in $\mathrm{H}_{2} \mathrm{O}$ and $\mathrm{CHCl}_{3}$ was added and mixed. The org. layer was washed with brine, dried $\left(\mathrm{Na}_{2} \mathrm{SO}_{4}\right)$, and evaporated to yield a tan colored powder.

Purification of Depsipeptides by RP-HPLC. The crude extract, dissolved in MeCN or MeOH, was centrifuged to obtain a light yellowish supernatant, which was injected into a semiprep. reverse-phase (RP) $C_{18}$ column fitted to a Hewlett-Packard 1100 series HPLC or an LKB HPLC system. Separation was achieved using $\mathrm{MeCN} / \mathrm{H}_{2} \mathrm{O}$ gradients $(40-70 \% \mathrm{MeCN})$. The HPLC profile showed two well-resolved peaks at MeCN contents of 65 and $68 \%$, resp. From a crude extract of $10 \mathrm{mg}, 2 \mathrm{mg}$ each of pure isaridin A and B were obtained.

Crystallization and X-Ray Structure Determination. The two peptides readily crystallized from the HPLC solvent mixtures (65 vs. $68 \%$ aq. $\mathrm{MeCN}$ ) upon standing for a few days. X-Ray data of the dry crystals were recorded at r.t. for both peptides. A crystal of isaridin A in the form of a wafer $(0.25 \times 0.25 \times 0.08 \mathrm{~mm})$ was used to collect data on a Bruker $C C D$ diffractometer with a high-intensity rotating anode $(\mathrm{Cu}$ radiation; $\lambda=$ $1.5418 \AA$ ). A total of 6687 independent reflections, with $I>2 \sigma(I)$ and a resolution of $0.84 \AA$, were used for the structure solution by direct phase determination and least-squares refinement. The crystal data for $\mathrm{C}_{39} \mathrm{H}_{53} \mathrm{~N}_{5} \mathrm{O}_{7} \cdot 2 \mathrm{H}_{2} \mathrm{O}$ are: space group $P 2_{1} 2_{1} 2_{1} ; a=10.3306(2), b=16.0519(4), c=24.3498(6) \AA ; Z=4, V=$ $4037.8 \AA^{3}, d_{\text {calc }}=1.218 \mathrm{gm} / \mathrm{cm}^{3} ; R_{1}=0.077$ for 479 parameters and 6687 reflections.

A crystal of isaridin B in the form of a prism $(0.30 \times 0.25 \times 0.25 \mathrm{~mm})$ was used to collect data on a Bruker P4 four-circle diffractometer with $\mathrm{Cu}$ radiation. A total of 2875 independent reflections, with $I>2 \sigma(I)$ and a resolution of $0.91 \AA$, were used for the structure solution by direct phase determination and least-squares refinement. The crystal data for $\mathrm{C}_{40} \mathrm{H}_{55} \mathrm{~N}_{5} \mathrm{O}_{7} \cdot 2 \mathrm{H}_{2} \mathrm{O}$ are: space group $P 1 ; a=9.583(1), b=10.186(1), c=$ 11.581(1), $\alpha=101.71(1)^{\circ}, \beta=107.84(1)^{\circ}, \gamma=94.98(1)^{\circ} ; Z=1, V=1040.1(2) \AA^{3}, d_{\text {calc }}=1.197 \mathrm{~g} / \mathrm{cm}^{3} ; R_{1}=0.043$ for 488 parameters and 2996 reflections.

Coordinates, bond lengths, bond angles, anisotropic thermal parameters for the C-, N-, and O-atoms, and coordinates for the H-atoms, have been deposited at the Cambridge Crystallographic Data Centre. The deposition numbers are CCDC 226028 and CCDC 226029 for isaridins A and B, resp.

NMR Experiments. All experiments were carried out in $\mathrm{CDCl}_{3}$ soln. on a Bruker DRX-500 spectrometer at $300 \mathrm{~K}$, with an inverse-detection probe, at a peptide conc. of $c a .5 \mathrm{~mm}$. Resonances were assigned by means of 2D-gradient COSY, TOCSY, and ROESY experiments. The TOCSY and ROESY 2D data were collected in phase-sensitive mode, with time-proportional phase incrementation (TPPI) in the indirect dimension. The spectral widths for all 2D experiments were set to $6000 \mathrm{~Hz}$. Sets of 1024 and 450 data points were used in $t_{2}$ and $t_{1}$ dimensions, resp. A total of 32 and 64 transients were collected in each experiment for TOCSY and ROESY, resp. For gradient COSY spectra, a data set of $1024 \times 256$ and eight transients per experiment were used. The ROESY spin-lock time was set to $300 \mathrm{~ms}$. All data sets were zero filled to yield a final data matrix of $1000 \times$ 1000. A shifted square sine-bell window was used before processing.

Mass Spectrometry. Electrospray ionization (ESI) mass spectra were recorded on a Hewlett-Packard singlequadrupole mass spectrometer ( $H P-1100-M S D$ series). The samples (crude extract) were infused into the spectrometer via a RP $C_{18}$ column (Zorbax; $\left.4.6 \times 150 \mathrm{~mm}\right)$ with solvent $A(0.1 \%$ aq. AcOH) and solvent $B$ ( $\mathrm{MeCN}$ with $0.1 \% \mathrm{AcOH}$ ) at a rate of $0.25 \mathrm{ml} / \mathrm{min}$. The gradient used was similar to the purification protocol (see above). The data were acquired over the range $\mathrm{m} / \mathrm{z} 50-3000$ in positive-ion mode, and were analyzed using the HP LC/MSD Chemstation software. Matrix-assisted laser-desorption-ionization time-of-flight (MALDITOF) MS analysis was carried out on a Kompact SEQ (Kratos Analytical, Manchester, UK) mass spectrometer, equipped with an $\mathrm{N}_{2}$ laser of $337 \mathrm{~nm}$ wavelength. The samples were prepared by mixing an equal amount of peptide $(0.5 \mu \mathrm{l})$ with a matrix soln. (' $\alpha$-cyano-4-hydroxycinnamic acid') saturated in solvent $B$.

\section{REFERENCES}

[1] J. W. Bennett, .R Bentley, Adv. Appl. Microbiol. 1989, 34, 1.

[2] R. Verpoorte, in 'Metabolic Engineering of Plant Secondary Metabolism', Eds. R. Verpoorte, A. W. Alfermann, Kluwer Academic Publishers, Dordrecht, 2000, p. 1. 
[3] 'Biotechnology: Products of Secondary Metabolism', Eds. H. Kleinkauf, H. von Döhren, John Wiley \& Sons, New York, 1997, Vol. 7.

[4] J. L. Adrio, A. L. Demain, Int. Microbiol. 2003, 3, 191.

[5] R. Baute, G. Deffieux, D. Merlet, M.-A. Baute, A. Neveu, J. Antibiot. 1981, 34, 1261.

[6] G. Deffieux, D. Merlet, R. Baute, G. Bourgeois, M.-A. Baute, A. Neveu, J. Antibiot. 1981, 34, 1266.

[7] D. Seebach, J. L. Matthews, Chem. Commun. 1997, 2015.

[8] G. W. Engstrom, J. V. DeLance, J. L. Richard, A. L. Baetz, J. Agric. Food Chem. 1975, 23, 244.

[9] A. Tsunoo, M. Kamijo, N. Taketomo, Y. Sato, K. Ajisaka, J. Antibiot. 1997, 50, 1007.

[10] E. M. Stocking, J. F. Sanz-Cervera, R. M. Williams, J. Am. Chem. Soc. 1996, 118, 7008.

[11] C. R. Gray, J. F. Sanz-Cervera, L. A. Silks, R. M. Williams, J. Am. Chem. Soc. 2003, 125, 14692.

[12] D. Schipper, J. Antibiot. 1983, 36, 1076.

[13] K. Umezawa, K. Nakazawa, T. Uemura, Y. Ikeda, S. Kondo, H. Naganawa, N. Kinoshita, H. Hashizume, M. Hamada, T. Takeuchi. S. Ohba, Tetrahedron Lett. 1988, 39, 1389.

[14] S. B. Krasnoff, D. M. Gibson, G. N. Belofsky, K. B. Gloer, J. B. Gloer, J. Nat. Prod. 1996, 59, 485.

[15] R. M. Williams. Chem. Pharm. Bull. 2002, 50, 711.

[16] J. L. Kellenberger, Ph.D. Thesis, ETH Zurich Switzerland, 1997.

[17] G. D. Rose, L. M. Gierasch, J. A. Smith, Adv. Protein Chem. 1985, 37, 1.

[18] I. L. Karle, in 'The Peptides', Eds. E. Gross, J. Meienhofer, Academic Press, New York, 1981, Vol 4, p. 1.

[19] J. S. Richardson, Adv. Protein Chem. 1981, 34, 167. 